\title{
Panorama of laryngeal lesions
}

Diouf MS*, Deguenonvo REA, Thiam A, Maiga S, Diop A, Regone E, Barry MW and Diouf R

ENT department of Grand Yoff General Hospital in Dakar, Senegal
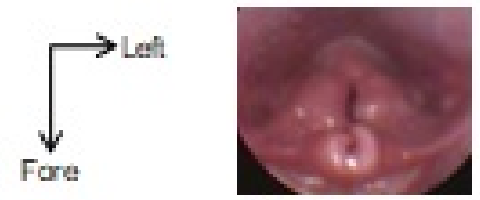

Laryngomalacla

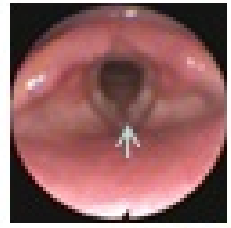

Klssing nodule

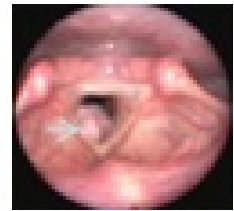

Laryngeal Papillomatosis

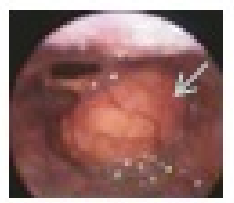

Vallecular Cyst

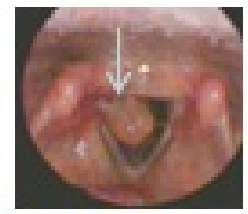

Glotto-supraglottc budding lesion suspect of mallgnancy

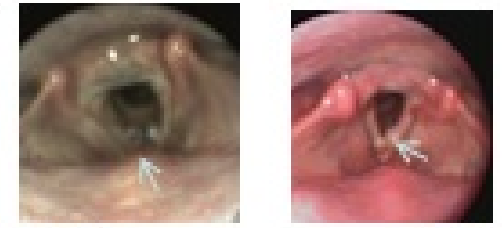

Klssing nodulg

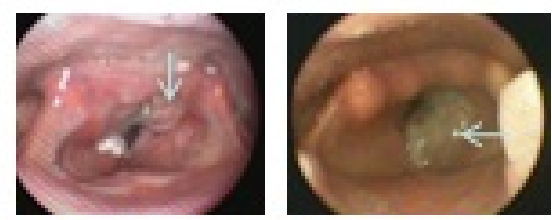

${ }^{3}{ }^{2}{ }^{2}$
Glottlc lesion suspect of mallgnancy

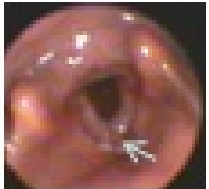

Glottlic lesion suspect of mallgnancy

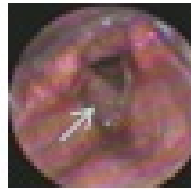

.

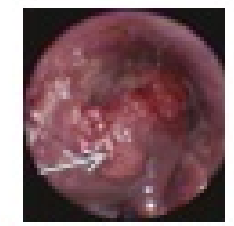

pharyngo-Laryngeal lesion suspect of mallgnancy

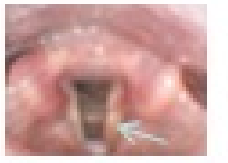

Sesslle polyps

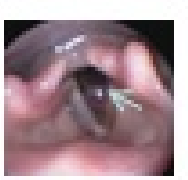

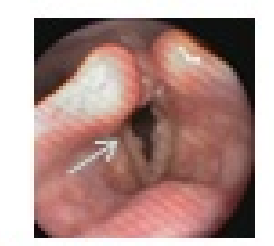

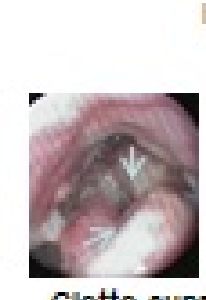

\section{Glotto-supragrottc} Infiltrative lesion suspect of mallgnancy

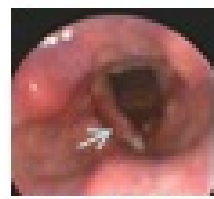

Chronic Laryngitls Left Recurrent Palb̈y

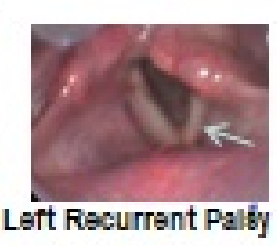

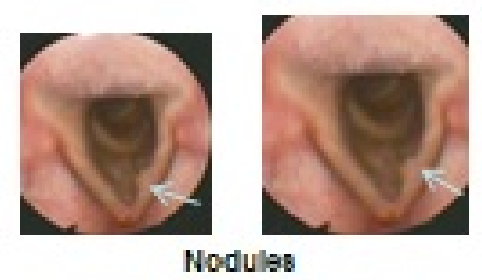

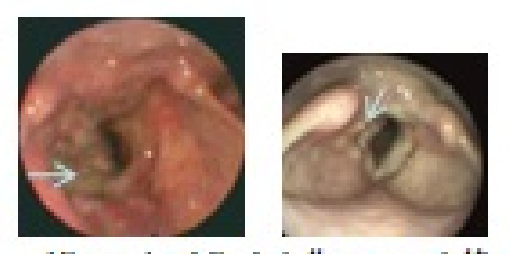

Ulcero-buddind glotto-supraglottc Leslon suspect of mallgnancy
Copyright: (C2018 Diouf MS. This is an open-access article distributed under the terms of the Creative Commons Attribution License, which permits unrestricted use, distribution, and reproduction in any medium, provided the original author and source are credited.

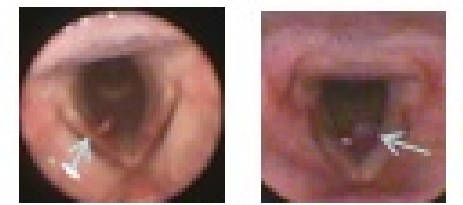

Sesslle polyps

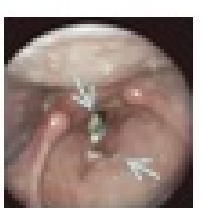

subglottic lesion

suspect of

mallgnancy

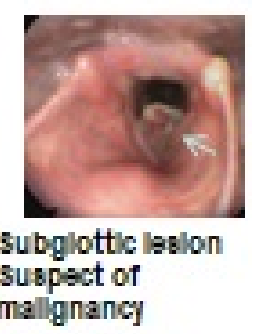

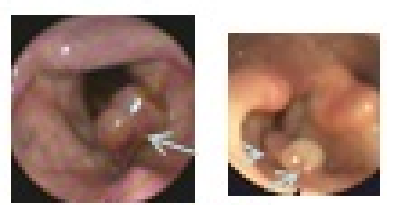

Pedicled Polyps

*Correspondence to: Mame Sanou Diouf, ENT department of Grand Yoff General Hospital in Dakar, Senegal, E-mail: sanou29@hotmail.com

Received: April 23, 2018; Accepted: April 28, 2018; Published: April 30, 2018 